\author{
Marc-Daniel Bollmann \\ Jean-Pierre Revelly \\ Luc Tappy \\ Mette M. Berger \\ Marie-Denise Schaller \\ Marie-Christine Cayeux \\ Alexandre Martinez \\ René-Louis Chioléro
}

\section{Effect of bicarbonate and lactate buffer on glucose and lactate metabolism during hemodiafiltration in patients with multiple organ failure}

Received: 10 September 2003

Accepted: 16 February 2004

Published online: 27 March 2004

(C) Springer-Verlag 2004
Electronic Supplementary Material Supplementary material is available in the online version of this article at http:// dx.doi.org/10.1007/s00134-004-2251-3

M.-D. Bollmann · J.-P. Revelly ·

M. M. Berger - M.-C. Cayeux .

A. Martinez - R.-L. Chioléro (®)

Surgical Intensive Care Unit,

University Hospital CHUV,

1011 Lausanne, Switzerland

e-mail: rene.chiolero@chuv.hospvd.ch

Tel.: +41-21-3142002

L. Tappy

Institute of Human Physiology,

University of Lausanne,

1005 Lausanne, Switzerland

M.-D. Schaller

Medical Intensive Care Unit,

University Hospital CHUV,

1011 Lausanne, Switzerland

\begin{abstract}
Objective: To compare the effects of sodium bicarbonate and lactate for continuous veno-venous hemodiafiltration (CVVHDF) in critically ill patients. Design and settings: Prospective crossed-over controlled trial in the surgical and medical ICUs of a university hospital. Patients: Eight patients with multiple organ dysfunction syndrome (MODS) requiring CVVHDF.

Intervention: Each patient received the two buffers in a randomized sequence over two consecutive days. Measurements and results: The following variables were determined: acid-base parameters, lactate production and utilization $\left({ }^{13} \mathrm{C}\right.$ lactate infusion), glucose turnover $\left(6,6^{2} \mathrm{H}_{2}-\right.$ glucose), gas exchange (indirect calorimetry). No side effect was observed during lactate administration. Baseline arterial acid-base variables were equal with the two buffers. Arterial lactate $(2.9$ versus $1.5 \mathrm{mmol} / \mathrm{l})$, glycemia $(+18 \%)$ and glucose turnover $(+23 \%)$ were higher in the lactate period. Bicarbonate and glucose losses in CVVHDF were substantial,
\end{abstract}

but not lactate elimination. Infusing

${ }^{13} \mathrm{C}$ lactate increased plasma lactate levels equally with the two buffers. Lactate clearance $(7.8 \pm 0.8$ vs $7.5 \pm$ $0.8 \mathrm{ml} / \mathrm{kg}$ per min in the bicarbonate and lactate periods) and endogenous production rates $(14.0 \pm 2.6$ vs $13.6 \pm$ $2.6 \mathrm{mmol} / \mathrm{kg}$ per min) were similar. ${ }^{13} \mathrm{C}$ lactate was used as a metabolic substrate, as shown by ${ }^{13} \mathrm{CO}_{2}$ excretion. Glycemia and metabolic rate increased significantly and similarly during the two periods during lactate infusion. Conclusion: Lactate was rapidly cleared from the blood of critically ill patients without acute liver failure requiring CVVHDF, being transformed into glucose or oxidized. Lactate did not exert undesirable effects, except moderate hyperglycemia, and achieved comparable effects on acid-base balance to bicarbonate.

Keywords Glucose turnover . Lactate oxidation $\cdot$ Strong ion difference $\cdot$ Continuous renal replacement therapy

\section{Introduction}

Continuous renal replacement therapy (CVVHDF) is currently used in critically ill patients with acute renal failure. Two buffers are usually used: sodium bicarbonate and sodium lactate. Bicarbonate is often claimed to be a better buffer in critically ill patients than lactate, since bicarbonate exerts direct acid-base effects, while lactate is dependent on tissue metabolism to exert its buffering effect [1]. These metabolic processes may become altered in patients with acute liver failure or refractory shock [2, 3]. Lactate may therefore accumulate and exert deleterious effects, but this is controversial [4]. In many other patients, there is no clear advantage in using bicarbonate. One argument suggests that lactate could even be a more efficient buffer: bicarbonate may promote tissue acidosis, 
due to the rapid penetration of carbon dioxide into the tissues, contrasting with the slow penetration of ions [5]. Another point to consider is related to the extracorporeal elimination of buffers by renal replacement therapy, which may also influence lactate and acid-base balances. Thus, the advantages and disadvantages of these two buffers remain to be established, particularly in patients with hyperlactatemia. Based on our previous work on lactate metabolism in severely ill patients $[6,7]$, we hypothesized that lactate would be actively metabolized in patients with multiple organ failure and hyperlactatemia requiring CVVHDF.

This prospective study was designed to compare the metabolic and acid-base effects of two different replacement solutions, containing either sodium bicarbonate or lactate, in critically ill patients requiring CVVHDF. The end points were lactate and glucose metabolism, as well as acid-base and electrolyte homeostasis.

\section{Material and methods}

Study population

The study was performed in the 17-bed surgical and 14-bed medical intensive care units of our university hospital over a 9-month period. With approval of the Institution Medical Ethics Review Board, we enrolled eight critically ill adult subjects in this crossedover controlled trial with a randomized sequence. Written informed consent was obtained from each patient or a relative.

Inclusion criteria were: age 16-75 years, acute renal failure requiring CVVHDF with at least one additional organ failure. Exclusion criteria were: blood lactate concentration more than $8 \mathrm{mmol} / \mathrm{l}$; chronic renal failure requiring dialysis; moribund patients unlikely to survive more than $48 \mathrm{~h}$; severe acute liver failure (defined as cytolysis, or factor $\mathrm{V}<30 \%$, and liver encephalopathy) and active hemorrhage preventing accurate metabolic determinations.
Table 1 Composition of the hemofiltration replacement solutions

\begin{tabular}{lcc}
\hline Concentration $(\mathrm{mmol} / \mathrm{l})$ & Bicarbonate & Lactate \\
\hline Lactate & 3 & 40 \\
$\mathrm{HCO}_{3}^{-}$ & 32 & 0 \\
$\mathrm{Na}^{+}$ & 140 & 140 \\
$\mathrm{Ca}^{++}$ & 1.75 & 1.75 \\
$\mathrm{Mg}^{++}$ & 0.5 & 0.75 \\
$\mathrm{Cl}^{+}$ & 109.5 & 105 \\
$\mathrm{~K}^{+}$ & 0 & 0 \\
\hline
\end{tabular}

Monitoring and treatments

Systemic and pulmonary arterial blood pressures were monitored (thermodilution catheter, Abott, North Chicago, IL, USA), cardiac output was measured by thermodilution. SAPS II score $(24 \mathrm{~h}$ after admission) [8] and the daily SOFA score [9] were recorded.

Continuous veno-venous hemodiafiltration was performed with a Prisma device (Gambro renal care products, Lakewood, $\mathrm{CO}$, USA). The filters (ANC 60) were changed before each $24 \mathrm{~h}$ protocol. Blood flow was set at $1.5-2.15 \mathrm{ml} / \mathrm{kg}$ per $\mathrm{h}$, dialysis flow at $15 \mathrm{ml} / \mathrm{kg}$ per $\mathrm{h}$ and filtration at $5 \mathrm{ml} / \mathrm{kg}$ per h. Replacement fluid was infused in the CVVHDF circuit as pre-dilution. The same fluid solution (Lactasol or Hemosol BO, Hospital, Lyon, France, Table 1) was used for dialysis and replacement. The ICU physician ordered fluid balance, automatically regulated by the extra-renal device. By design, the effluent fluid composition results from the effect of both filtration and dialysis: therefore effluent fluid indicates the net effect of these two processes.

\section{Experimental protocol and measurements}

Each patient received two different CVVHDF solutions containing sodium bicarbonate or lactate in a randomized sequence over two consecutive 24-h periods. The measurements (Fig. 1) were performed during the last $6 \mathrm{~h}$ of each 24-h period. During the last $3 \mathrm{~h}$ exogenous sodium lactate was infused to assess lactate pharmacokinetics (lactate test) [10].

All fluid inputs and outputs were recorded, including residual diuresis. Arterial and effluent fluid acid-base variables were measured hourly using a blood gas analyzer (Rapidlab Model 865 blood gas analyser, Ciba-Corning Diagnostics, Switzerland). Hourly substrate balances were calculated as the differences between the inputs of all intravenous and enteral fluids and outputs determined from CVVHDF effluents and residual diuresis.

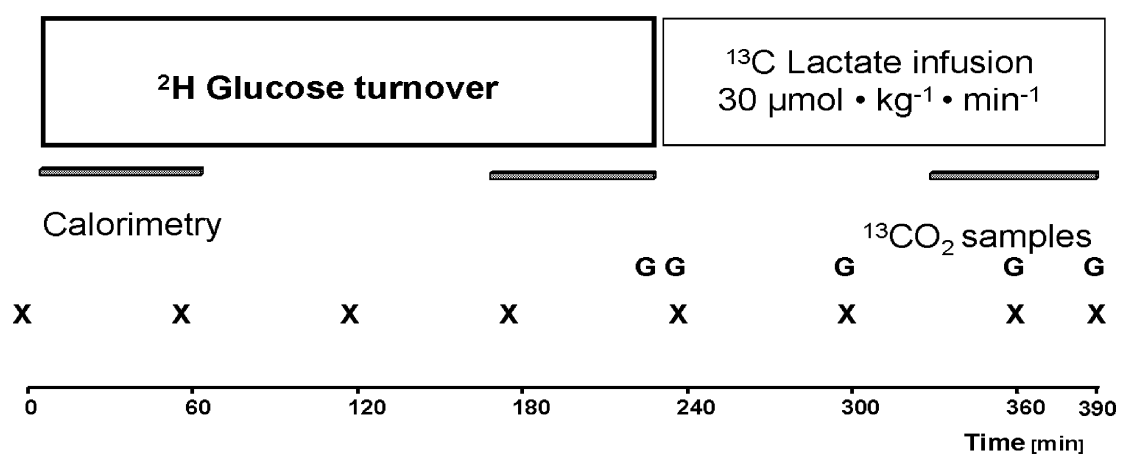

Fig. 1 Diagram of the protocol performed in eight patients during continuous veno-venous hemodiafiltration (CVVHDF) with lactate and bicarbonate buffer in a sequential manner. $G$ glucose sampling for $6,6^{2} \mathrm{H}_{2}$ glucose enrichment, $X$ blood and CVVHDF effluent sampling, and hemodynamic measurements 
In terms of a lactate test, lactate production and utilization were determined using a pharmacokinetic model, based on the infusion of an exogenous load of lactate [10], combined with an isotope dilution method. A continuous infusion of $30 \mu \mathrm{mol} / \mathrm{kg}$ per min sodium lactate, labeled with ${ }^{13} \mathrm{C}$ lactate, was administered during 180 min. Breath samples were collected (hexatainers, Europa Scientific Crew, UK) in quadruplicate $30 \mathrm{~min}$ immediately before lactate infusion and every $30 \mathrm{~min}$ thereafter to determine ${ }^{13} \mathrm{CO}_{2}$ excretion (as a reflection of lactate overall oxidation).

Glucose turnover was determined by means of an isotope dilution method. After the determination of basal glucose isotope enrichment, a primed, continuous infusion of $6,6^{2} \mathrm{H}_{2}$-glucose (prime $6.7 \mu \mathrm{mol} / \mathrm{kg}$ per min, corrected for fasting plasma glucose, continuous $0.33 \mu \mathrm{mol} / \mathrm{kg}$ per min) was started. After $2.5 \mathrm{~h}$, two blood samples were collected at a 30-min interval for the calculation of glucose turnover. Resting oxygen consumption $\left(\mathrm{V}_{2}\right)$ and $\mathrm{CO}_{2}$ production $\left(\dot{\mathrm{V} C \mathrm{C}_{2}}\right)$ were measured during $60 \mathrm{~min}$ prior to and during the last hour of lactate infusion, using a Deltatrac indirect calorimeter (Datex Instruments, Helsinki, Finland) from ventilator expiratory gases. Resting energy expenditure was calculated with the equations of Livesey and Elia [11].

\section{Analytical procedures (see detailed description in ESM)}

Plasma $6,6{ }^{2} \mathrm{H}$-glucose was measured with GC-MS on a Hewlett Packard instrument (GC 5890-MS 5971, Hewlett Packard, Palo Alto, CA). The strong ion difference was calculated using a simplified Stewart's equation: $\operatorname{SID}_{\mathrm{app}}=\left(\mathrm{Na}^{+}+\mathrm{K}^{+}\right)-\left(\mathrm{Cl}^{-}+\mathrm{lactate}^{-}\right)$[12]. The concentrations of plasma insulin (kit from Biochem Immunosystems, Freiburg, Germany), cortisol (kit from Diagnostic Products, Los Angeles, CA) and glucagon (kit from Linco Research, St Charles, MO) were determined.

\section{Calculations (see detailed equations in ESM)}

The pharmacological clearance of lactate was calculated from the lactate infusion rate and changes in plasma lactate levels, using the standard pharmacokinetic calculation and taking into account CVVHDF lactate elimination. Assuming that endogenous lactate production was not altered by exogenous lactate [13], the former was calculated as the product of basal lactate concentration and lactate clearance during bicarbonate CVVHDF [10]. During lactate
CVVHDF, lactate administration by CVVHDF solutions was subtracted. Lactate oxidation was determined from ${ }^{13} \mathrm{CO}_{2}$ pulmonary excretion. Glucose turnover was calculated with Steele's equations [14].

\section{Statistical analysis}

The results are expressed as means \pm SD. Comparisons between groups and comparisons over time were carried out with two-way ANOVA for the effect of treatment group and time. Post hoc comparisons were made with Scheffé and Dunett's tests where appropriate. Statistical analysis was performed using JMP Statistical software (version 3.5.1, SAS Institute, Cary, NC). Probability less than 0.05 was considered as statistically significant.

\section{Results}

The main characteristics of the patients are described in Table 2. All were mechanically ventilated and suffered from multiple organ failure (4-6 acute organ failures). Five patients died during the ICU stay, one after transfer to the ward and two were discharged alive from the hospital. Predicted mortality according to SAPS II scores was about $60 \%$.

Continuous veno-venous hemodiafiltration with both buffers was well tolerated by all patients: no side effect related to extra-renal therapy was observed, except isolated hyperlactatemia during lactate administration. Neither hemodynamic variables nor catecholamine administration were different in the two treatment periods (Table 3). CVVHDF settings as well as fluid balances were similar over the two periods (Table 4).

Table 2 Patient characteristics

\begin{tabular}{|c|c|c|c|c|c|c|c|c|c|c|}
\hline No. & Age & Sex & Admission diagnosis & BMI & SAPS II & SOFA & $\begin{array}{l}\text { No. } \\
\text { failures }\end{array}$ & LICU & Main complications & Outcome \\
\hline 1 & 77 & $\mathrm{~F}$ & $\begin{array}{l}\text { Abdominal aorta } \\
\text { surgery }\end{array}$ & 28.3 & 52 & 11 & 6 & 10 & Septic shock, hemorrhage & Died \\
\hline 2 & 68 & $\mathrm{~F}$ & $\begin{array}{l}\text { Abdominal aorta } \\
\text { surgery }\end{array}$ & 25.1 & 48 & 17 & 6 & 24 & Ischemic colitis Pneumonia & Alive \\
\hline 3 & 55 & M & $\begin{array}{l}\text { Abdominal aorta } \\
\text { surgery }\end{array}$ & 32.4 & 43 & 12 & 4 & 8 & $\begin{array}{l}\text { Paraplegia, ischemic } \\
\text { colorectitis }\end{array}$ & Alive \\
\hline 4 & 59 & M & Abdominal sepsis & 28.3 & 31 & 8 & 4 & 18 & Pneumonia, metabolic coma & Alive \\
\hline 5 & 72 & M & Cardiac surgery & 28.3 & 51 & 14 & 5 & 28 & $\begin{array}{l}\text { Mediastinitis, pneumonia, } \\
\text { septic shock }\end{array}$ & Died \\
\hline 6 & 61 & $\mathrm{~F}$ & Endocarditis & 24.8 & 77 & 19 & 6 & 8 & $\begin{array}{l}\text { Cardiac failure, hemiplegia, } \\
\text { septic shock }\end{array}$ & Died \\
\hline 7 & 67 & M & Myocardial infarct & 32.0 & 76 & 17 & 5 & 21 & Cardiac failure, hemorrhage & Died \\
\hline 8 & 63 & $\mathrm{M}$ & $\begin{array}{l}\text { Abdominal aorta } \\
\text { surgery }\end{array}$ & 26.0 & 94 & 13 & 4 & 14 & Septic shock, hemorrhage & Died \\
\hline
\end{tabular}

$B M I$ body mass index, SAPS simplified acute physiology score, SOFA sepsis-related organ failure score at initiation of the study, $L I C U$ length of ICU stay, ARF acute renal failure, No. failures number of end organ failures including renal failure - maximum 6

Patient 4 died 1 month after leaving ICU 
Table 3 Hemodynamic, acidbase and chemistry values

\begin{tabular}{|c|c|c|c|c|}
\hline & \multicolumn{2}{|c|}{$\begin{array}{l}\text { Continuous veno-venous } \\
\text { hemodiafiltration }\end{array}$} & \multicolumn{2}{|l|}{ Lactate test } \\
\hline & Bicarbonate & Lactate & Bicarbonate & Lactate \\
\hline \multicolumn{5}{|l|}{ Hemodynamics } \\
\hline Dobutamine $(\mu \mathrm{g} / \mathrm{min}$ per $\mathrm{kg})$ & $4.9 \pm 3.5$ & $4.8 \pm 3.8$ & $4.8 \pm 4.4$ & $4.8 \pm 4.2$ \\
\hline Norepinephrine (ng/min per $\mathrm{kg}$ ) & $55 \pm 57$ & $52 \pm 54$ & $24 \pm 26$ & $25 \pm 27$ \\
\hline Cardiac index $\left(1 / \mathrm{min}\right.$ per $\left.\mathrm{m}^{2}\right)$ & $2.4 \pm 1.1$ & $2.6 \pm 1.1$ & $3.0 \pm 1.5^{\mathrm{a}}$ & $2.9 \pm 1.3^{\mathrm{a}}$ \\
\hline \multicolumn{5}{|l|}{ Acid-base variables } \\
\hline pH blood & $7.44 \pm 0.07$ & $7.44 \pm 0.11$ & $7.51 \pm 0.07^{\mathrm{a}}$ & $7.49 \pm 0.11^{\mathrm{a}}$ \\
\hline $\mathrm{PCO}_{2}$ blood $(\mathrm{mmHg})$ & $40.5 \pm 6.4$ & $39.2 \pm 6.0$ & $40.2 \pm 6.8$ & $40.0 \pm 7.0$ \\
\hline $\mathrm{HCO}_{3}$ blood $(\mathrm{mmol} / \mathrm{l})$ & $26.6 \pm 3.6$ & $25.8 \pm 4.8$ & $31.1 \pm 4.3$ & $29.6 \pm 5.3$ \\
\hline \multicolumn{5}{|l|}{ Plasma chemistry } \\
\hline $\mathrm{Na}^{+}(\mathrm{mmol} / \mathrm{l})$ & $136 \pm 4$ & $136 \pm 3$ & $144 \pm 3^{\mathrm{a}}$ & $144 \pm 2^{\mathrm{a}}$ \\
\hline $\mathrm{K}^{+}(\mathrm{mmol} / \mathrm{l})$ & $4.1 \pm 0.3$ & $4.1 \pm 0.3$ & $3.8 \pm 0.4$ & $3.8 \pm 0.4$ \\
\hline $\mathrm{Cl}^{-}(\mathrm{mmol} / \mathrm{l})$ & $105 \pm 2$ & $106 \pm 3$ & $106 \pm 2$ & $106 \pm 3$ \\
\hline Lactate (mmol/l) & $1.7 \pm 0.3$ & $3.3 \pm 1.2^{\mathrm{b}}$ & $5.7 \pm 1.1^{\mathrm{a}}$ & $7.7 \pm 2.4^{\mathrm{a}}$ \\
\hline Pyruvate $(\mu \mathrm{mol} / \mathrm{l})$ & $113 \pm 30$ & $174 \pm 52^{\mathrm{b}}$ & $274 \pm 78^{\mathrm{a}}$ & $331 \pm 109^{\mathrm{a}}$ \\
\hline Lactate/pyruvate blood & $13.5 \pm 2.1$ & $16.5 \pm 2.8^{b}$ & $20.1 \pm 5.7^{\mathrm{a}}$ & $21.6 \pm 3.3^{\mathrm{a}}$ \\
\hline Strong ion difference $(\mathrm{meq} / \mathrm{l})$ & $33.3 \pm 2.7$ & $31.5 \pm 3.6$ & $37.1 \pm 2.6^{\mathrm{a}}$ & $35.6 \pm 4.5^{\mathrm{a}}$ \\
\hline Albumin (g/l) & $17 \pm 3$ & $18 \pm 3$ & & \\
\hline Creatinine $(\mu \mathrm{mol} / \mathrm{l})$ & $202 \pm 83$ & $179 \pm 57$ & & \\
\hline Glucose $(\mathrm{mmol} / \mathrm{l})$ & $8.2 \pm 2.2$ & $10.0 \pm 2.9^{\mathrm{b}}$ & $9.1 \pm 2.6^{\mathrm{a}}$ & $10.9 \pm 3.1^{\mathrm{a}, \mathrm{b}}$ \\
\hline \multicolumn{5}{|c|}{ Continuous veno-venous hemodiafiltration effluent } \\
\hline $\mathrm{HCO}_{3}(\mathrm{mmol} / \mathrm{l})$ & $28.6 \pm 4.2$ & $24.1 \pm 3.8^{\mathrm{b}}$ & $32.3 \pm 4.2$ & $27.6 \pm 4.3$ \\
\hline Lactate $(\mathrm{mmol} / \mathrm{l})$ & $1.8 \pm 0.3$ & $7.6 \pm 2.0^{\mathrm{b}}$ & $5.6 \pm 1.4^{\mathrm{a}, \mathrm{b}}$ & $12.1 \pm 3.8^{\mathrm{a}, \mathrm{b}}$ \\
\hline Glucose $(\mathrm{mmol} / \mathrm{l})$ & $7.5 \pm 2.2$ & $9.5 \pm 2.9^{b}$ & $8.6 \pm 2.4^{\mathrm{a}}$ & $9.7 \pm 3.2^{\mathrm{a}, \mathrm{b}}$ \\
\hline
\end{tabular}

${ }^{\mathrm{a}}$ Different from baseline with the same buffer; ${ }^{\mathrm{b}}$ different from bicarbonate buffer at the same time point, $p<0.05$
Table 4 Main continuous veno-venous hemodiafiltration (CVVHDF) parameters, means $\pm \mathrm{SD}$, in $\mathrm{ml} / \mathrm{min} \cdot$ per $\mathrm{kg}$

\begin{tabular}{lcc}
\hline & Bicarbonate & Lactate \\
\hline Blood flow rate & $1.7 \pm 0.3$ & $1.7 \pm 0.3$ \\
Dialysate flow rate & $15.0 \pm 2.5$ & $14.6 \pm 2.4$ \\
Hemofiltration flow rate & $5.4 \pm 2.5$ & $5.9 \pm 3.6$ \\
Effluent flow rate & $21.5 \pm 3.7$ & $21.7 \pm 4.4$ \\
Fluid balance & $-0.08 \pm 0.07$ & $-0.08 \pm 0.07$ \\
\hline
\end{tabular}

Acid base and electrolytes

Arterial $\mathrm{pH}, \mathrm{PCO}_{2}$ and bicarbonate were equal with the two buffers (Table 3). This was also the case for the $\mathrm{SID}_{\text {app }}$ that was moderately reduced over the two periods compared with normal values (44 meq/l) [12]. Albumin concentrations were equally low during the two periods, contributing to a normal $\mathrm{pH}$ despite reduced $\mathrm{SID}_{\text {app }}$ (Table 3).

Bicarbonate loss in the CVVHDF effluent was substantial, amounting to $800-1000 \mathrm{mmol} / \mathrm{day}$ in the two groups. By contrast, lactate elimination was small, amounting to $150 \mathrm{mmol} / \mathrm{day}(5.5 \pm 3.3 \%$ of the lactate supplied) with lactate buffer and $70 \mathrm{mmol} /$ day with bicarbonate $(4.7 \pm 2.2 \%)$. Plasma electrolyte concentration was not different during the two periods (Table 3).
Metabolic variables

Basal arterial lactate concentrations were significantly higher in the lactate compared to the bicarbonate period (mean values 3.3 versus $1.7 \mathrm{mmol} / \mathrm{l}, p<0.0001$ ) (Table 3 ). Baseline glycemia (+23\%) and glucose turnover $(+20 \%)$ were significantly higher during the lactate period $(\mathrm{Ta}-$ ble 5). Glucose loss in the CVVHDF amounted to about $60 \mathrm{~g} /$ day in the two periods (Table 3).

Compared with normal values, the baseline resting metabolic rate was moderately increased with the two buffers (Table 5). The mean baseline arterial pyruvate concentration and lactate-pyruvate ratio were higher during the lactate period (Table 3, $p=0.009$ ).

Both cortisol and glucagon plasma levels were high over the study (Table 3 ) and did not differ between buffers.

${ }^{13} \mathrm{C}$ Lactate infusion test

Infusing ${ }^{13} \mathrm{C}$ lactate increased equally the plasma lactate levels in the two periods. Lactate clearance was similar during the two periods: $7.8 \pm 0.8$ versus $7.5 \pm 0.8 \mathrm{ml} / \mathrm{kg}$ per min with bicarbonate and lactate, respectively. Endogenous lactate production rates were also similar: 14.0 \pm 2.6 versus $13.6 \pm 2.6 \mu \mathrm{mol} / \mathrm{kg}$ per $\mathrm{min}$ in the bicarbonate and lactate periods, respectively (Fig. 2, Table 5). ${ }^{13} \mathrm{C}$ lactate 
Table 5 Metabolic values

\begin{tabular}{|c|c|c|c|c|}
\hline & \multicolumn{2}{|c|}{ Continuous veno-venous hemodiafiltration } & \multicolumn{2}{|l|}{ Lactate test } \\
\hline & Bicarbonate & Lactate & Bicarbonate & Lactate \\
\hline $\begin{array}{l}\text { Energy expenditure }(\mathrm{kCal} / 24 \mathrm{~h}) \\
\text { Respiratory quotient } \\
\mathrm{VCO}_{2}(\mathrm{ml} / \mathrm{min}) \\
\mathrm{VO}_{2}(\mathrm{ml} / \mathrm{min}) \\
\text { Glucose }(\mathrm{mmol} / \mathrm{l}) \\
\text { Glucose turnover }(\mu \mathrm{mol} / \mathrm{kg} \text { per } \mathrm{min}) \\
\text { Lactate clearance }(\mathrm{ml} / \mathrm{kg} \text { per min }) \\
\text { Endogenous production of lactate }(\mu \mathrm{mol} / \mathrm{kg} \text { per min }) \\
\text { Insulin }(\mathrm{pmol} / \mathrm{l}) \\
\text { Glucagon }(\mathrm{ng} / \mathrm{l}) \\
\text { Cortisol }(\mathrm{nmol} / \mathrm{l})\end{array}$ & $\begin{array}{c}1684 \pm 425 \\
0.87 \pm 0.11 \\
210 \pm 54 \\
244 \pm 64 \\
8.2 \pm 2.2 \\
19.4 \pm 1.12\end{array}$ & $\begin{array}{c}1581 \pm 339 \\
0.86 \pm 0.11 \\
195 \pm 44 \\
229 \pm 54 \\
10.0 \pm 2.9^{\mathrm{b}} \\
23.3 \pm 1.1^{\mathrm{b}}\end{array}$ & $\begin{array}{c}1884 \pm 397^{\mathrm{a}} \\
0.83 \pm 0.12^{\mathrm{a}} \\
230 \pm 47^{\mathrm{a}} \\
281 \pm 60^{\mathrm{a}} \\
9.1 \pm 2.6^{\mathrm{a}} \\
7.8 \pm 0.8 \\
14.0 \pm 2.6\end{array}$ & $\begin{array}{c}1790 \pm 295^{\mathrm{a}} \\
0.81 \pm 0.08^{\mathrm{a}} \\
210 \pm 42^{\mathrm{a}} \\
260 \pm 53^{\mathrm{a}} \\
10.9 \pm 3.1^{\mathrm{a}, \mathrm{b}} \\
7.5 \pm 0.8 \\
13.6 \pm 2.6\end{array}$ \\
\hline
\end{tabular}

${ }^{\mathrm{a}}$ different from baseline with the same buffer, ${ }^{\mathrm{b}}$ different from bicarbonate buffer at the same time point, $p<0.05$.

$\mathrm{VCO}_{2}$ carbon dioxide excretion, $\mathrm{VO}_{2}$ oxygen consumption

Fig. 2 Lactate pharmacokinetics and ${ }^{13} \mathrm{C}$ lactate oxidation in patients receiving continuous renal replacement therapy with either sodium bicarbonate or lactate as buffer
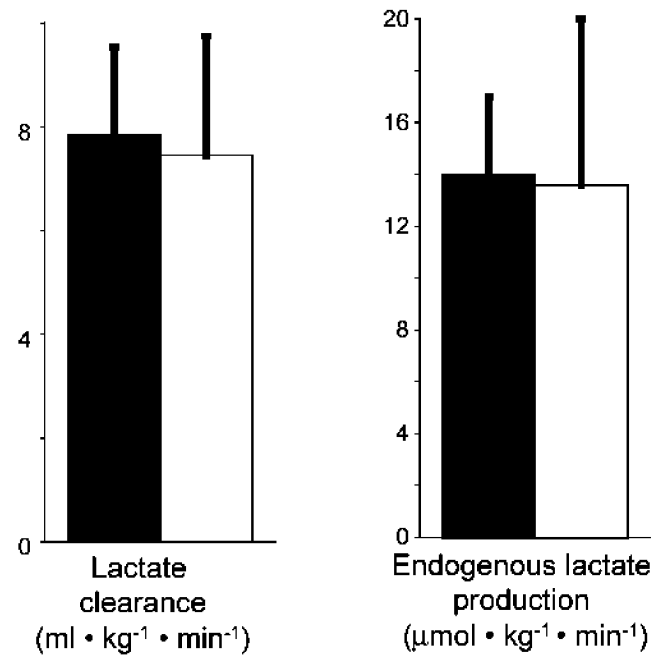

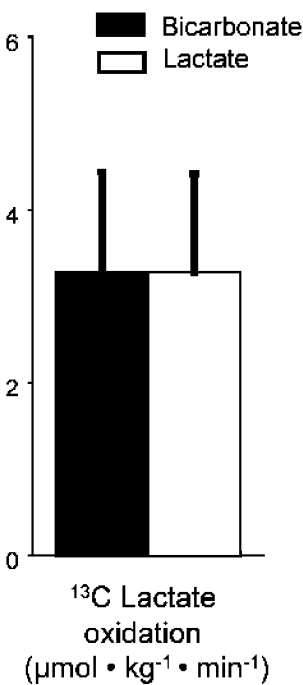

was actively used as an energetic substrate, as shown by the rapid appearance of ${ }^{13} \mathrm{CO}_{2}$ in expired gas (Fig. 2).

During ${ }^{13} \mathrm{C}$ lactate infusion, glycemia, pyruvate and the lactate/pyruvate ratio significantly increased in the two periods (Table 3). There were significant and similar increases in arterial $\mathrm{pH}$, bicarbonate and $\mathrm{SID}_{\text {app }}$ in both groups (Table 3). Plasma $\mathrm{Na}^{+}$increased markedly (+8.5 mmol/l) while plasma $\mathrm{Cl}^{-}$did not change (Table 3$)$. The resting metabolic rate, oxygen consumption and carbon dioxide production all increased significantly. Cardiac index increased significantly and equally in the two periods after lactate infusion.

\section{Discussion}

This study compared the effects of two CVVHDF solutions, containing either lactate or bicarbonate, in patients with multiple organ dysfunctions. The results show that lactate administered with the CVVHDF solutions was well tolerated, efficiently metabolized and exerted similar acid-base effects to bicarbonate. Lactate increased glucose turnover and glucose plasma level secondary to stimulation of gluconeogenesis. The glucose loss in CVVHDF was substantial.

\section{Buffers for continuous veno-venous hemodiafiltration}

The use of lactate and bicarbonate buffers remains controversial, particularly the risks related with lactate accumulation in patients with metabolic failure. Sodium lactate is cheap, stable and available in ready-for-use solutions. Bicarbonate exerts direct buffering effects, but bicarbonate-containing solutions must be prepared before use, due to the instability of bicarbonate solutions. In patients with severe tissue dysoxia or liver failure, lactic acidosis is commonly observed and correlated with mortality $[15,16]$. This led to the assumption that exogenous lactate may be harmful and promoted the use of 
bicarbonate-buffered solutions [2, 17, 18, 19, 20, 21, 22]. A large exogenous lactate load should be avoided in patients with lactic acidosis for two reasons: first, the decreased ability of the body to use lactate and, second, the better hemodynamic stability with bicarbonate $[17,20$, $22,23]$. However, recent data show that exogenous lactate is rapidly metabolized in patients with postoperative cardiogenic shock or extensive liver resection $[6,7]$. The major problem in patients with hyperlactatemia is, therefore, more related to the underlying medical condition than to the toxic effect of lactate per se. The inability of dichloroacetate, a compound increasing pyruvate and lactate utilization, to influence the clinical outcome in critically ill patients with lactic acidosis, despite significant reduction of lactate blood level, highlights this fact [24].

Lactate and glucose metabolism

in continuous veno-venous hemodiafiltration

Lactate synthesis increases in conditions where glycolysis is stimulated [25]. Plasma lactate increases when pyruvate generation exceeds utilization or when pyruvate utilization is altered by tissue dysoxia. In the latter condition, anaerobic metabolism leads to the development of lactic acidosis [26, 27], where acidosis is related to the hydrolysis of the ATPs generated during anaerobic glycolysis and not to lactate metabolism per se.

After conversion into pyruvate, lactate has several metabolic fates: mainly oxidation in the tricarboxylic cycle, as well as transformation into glucose in the liver and kidney. In these pathways, lactate utilization is associated with the consumption of protons, which is equivalent to the generation of bicarbonate [28]. During aerobic lactate metabolism there is no net acid production and the acid-base balance remains in equilibrium [25].

Blood lactate is dependent on the balance between lactate production and utilization. In the present study, lactate infusion led to similar metabolic changes with both buffers: increases in arterial lactate, pyruvate and glucose concentrations, associated with a rise of arterial $\mathrm{pH}$ and bicarbonate as well as increases in energy expenditure. All these findings may be explained by active lactate metabolism: transformation of lactate into pyruvate, an increase in glucose production in the gluconeogenesis process, generation of plasma bicarbonate consecutive to lactate metabolism, a rise in oxygen consumption and metabolic rate related to the thermic effect of lactate $[25,28]$. The isotopic measurements, showing the generation of ${ }^{13} \mathrm{CO}_{2}$ following the infusion of ${ }^{13} \mathrm{C}$ lactate confirm the findings of the pharmacokinetic model.

Lactate clearance rates observed in the present study were moderately decreased in comparison with the values that we previously reported in healthy subjects and in surgical patients using similar methods [7]. This was little influenced by the extracorporeal elimination of lactate by CVVHDF, which was low, in accordance with previous studies [29]. This low clearance rate may be related to the poor clinical condition of the study population, characterized by multiple organ failure and high ICU mortality. The latter was very high (approximately 60\%), as expected according to their medical condition [30]. Interestingly, despite this altered lactate utilization, lactate administered in CVVHDF fluids and lactate test was rapidly metabolized, illustrating the large capacity of tissues to use lactate.

Compared with normal values observed in healthy subjects (approximately $10 \mu \mathrm{mol} / \mathrm{kg}$ per min), endogenous production of lactate was increased in our patients, like in postoperative surgical patients or cardiac surgery patients with acute circulatory failure [6, 7]. Several mechanisms may concur to increase lactate synthesis in the body: (1) sympathoadrenal activation leads to stimulation of the $\mathrm{Na}^{+} / \mathrm{K}^{+}$ATPase and lactate synthesis [31] was likely in our patients treated with catecholamines; (2) proinflammatory cytokines [32]; (3) elevated glucose turnover and cycling, both phenomena associated with increased glycolysis and (4) lactate production by inflammatory cells, wounds and diseased organs [33].

To our knowledge, this is the first study comparing lactate and glucose metabolism in patients receiving sodium lactate and bicarbonate for CVVHDF, using pharmacokinetic and isotopic methods. Two studies were previously performed in critically ill patients using a similar approach. In the first, patients under CVVHDF with bicarbonate buffer and normal lactatemia were observed [29]. Total lactate clearance amounted to $15 \mathrm{ml} / \mathrm{kg}$ per min and lactate elimination by CVVHDF was low, like in our study. Endogenous lactate production amounted to $20 \mu \mathrm{mol} / \mathrm{kg}$ per min. In the second, septic patients without renal failure were studied, with either normal or elevated lactate levels [34]. Lactate clearances were higher in the former than in the latter group, while endogenous lactate production was similar in the two groups. Although it seems difficult to compare lactate metabolism in patients with such different clinical conditions, increased lactate production was observed in all these studies, while lactate clearance was maintained or altered, according to organ and system failure.

Finally, higher glycemia and glucose turnover were observed during lactate CVVHDF and lactate test, suggesting that the auto-regulation of glucose endogenous production was abolished. Indeed, glucose endogenous production stays constant during the administration of precursors of gluconeogenesis (like lactate) in healthy and in critically ill subjects receiving TPN $[35,36]$. This indicates that the regulation of glucose metabolism was altered in our patients. 
Sodium lactate versus bicarbonate as buffer for continuous veno-venous hemodiafiltration

Several trials have compared sodium lactate and bicarbonate for CVVHDF [17, 20, 21, 22, 37]. Studies report similar effects of lactate- and bicarbonate-buffered solutions on acid-base balance [17, 20, 21, 37], while others suggest that correction of acidosis may be delayed or less efficacious with lactate [22]. This contrasts with the data in patients with acute liver failure or hepatorenal syndrome, where lactate metabolism is altered in parallel to its buffering capacity $[3,18]$. In the present study, lactate and bicarbonate exerted equivalent acid-base effects. The price paid for lactate administration was a moderate increase in lactate and glucose blood levels. Of note, acidbase status was in the normal range in our patients; this may have influenced lactate metabolism, which is known to be depressed in severe acidosis [26]. The baseline lactate/pyruvate ratio was not higher with lactate buffer and increased in the two periods during ${ }^{13} \mathrm{C}$ lactate infusion. We have no clear explanation for this finding: it might reflect a mass effect related to exogenous lactate administration or disturbed intracellular redox state.

Our study provides new arguments to demonstrate that lactate is a convenient substrate in most critically ill patients requiring CVVHDF. This may not be true in patients with severe liver failure or lactic acidosis, since the experimental and human data clearly show the major importance of liver function in lactate and acid-base metabolism.

In conclusion, lactate administered as a buffer for CVVHDF was rapidly metabolized in critically ill patients with multiple organ failure, without acute liver failure. It was rapidly cleared from the blood, being transformed into glucose or oxidized, as demonstrated by combined pharmacokinetic and isotopic methods. Comparison with bicarbonate buffer showed that lactate did not exert undesirable metabolic effects, except a moderate rise of lactate and glucose blood levels. Lactate and bicarbonate buffers achieved comparable effects on acidbase balance.

\section{References}

1. Panichi V, Parrini M, Bianchi AM, Andreini B, Cirami C, Finato V, Palla R (1994) Mechanisms of acid-base homeostasis in acetate and bicarbonate dialysis, lactate hemofiltration and hemodiafiltration. Int J Artif Organs $17: 315-321$

2. Davenport A, Will EJ, Davison AM (1991) Hyperlactataemia and metabolic acidosis during haemofiltration using lactate-buffered fluids. Nephron 59:461-465

3. Hilton PJ, Taylor J, Forni LG, Treacher DF (1998) Bicarbonate-based haemofiltration in the management of acute renal failure with lactic acidosis QJM 91:279-283

4. Benjamin E (1997) Continuous venovenous hemofiltration with dialysis and lactate clearance in critically ill patients. Crit Care Med 25:4-5

5. Viallon A, Zeni F, Lafond P, Venet C, Tardy B, Page Y, Bertrand JC (1999) Does bicarbonate therapy improve the management of severe diabetic ketoacidosis? Crit Care Med 27:2690-2693

6. Chioléro R, Revelly JP, Leverve X, Gersbach Ph, Cayeux MC, Berger MM, Tappy L (2000) Effects of cardiogenic shock on lactate and glucose metabolism after heart surgery. Crit Care Med 28:3784-3791
7. Chioléro RL, Tappy L, Gillet M, Revelly JP, Roth H, Cayeux MC, Schneiter P, Leverve X (1999) Effect of major hepatectomy on glucose and lactate metabolism. Ann Surg 229:505513

8. LeGall JR, Lemeshow S, Saulnier F (1993) A new simplified acute physiology score (SAPS II) based on a European/North American multicenter study. JAMA 270:2957-2963

9. Vincent JL, Moreno R, Takala J, Willatts S, De Mendonca A, Bruining H, Reinhart CK, Suter PM, Thijs LG (1996) The SOFA (Sepsis-related Organ Failure Assessment) score to describe organ dysfunction/failure. On behalf of the Working Group on Sepsisrelated Problems of the European Society of Intensive Care Medicine. Intensive Care Med 22:707-710

10. Connor H, Woods HF, Ledingham JGG, Murray JD (1982) A model of $\mathrm{L}(+)$-lactate metabolism in normal man. Ann Nutr Metab 26:254-263

11. Livesey G, Elia M (1988) Estimation of energy expenditure, net carbohydrate utilization, and net fat oxidation and synthesis by indirect calorimetry: evaluation of errors with special reference to the detailed composition of fuels. Am J Clin Nutr 47:608-628

12. Stewart PA (1978) Independent and dependent variables of acid-base control. Respir Physiol 33:9-26
13. Jenssen T, Nurjhan N, Consoli A, Gerich JE (1993) Dose-response effects of lactate infusions on gluconeogenesis from lactate in normal man. Eur J Clin Invest 23:448-454

14. DeBodo R, Steele R, Altszuler N, Dunn A, Bishop J (1963) On the hormonal regulation of carbohydrate metabolism: studies with ${ }^{14} \mathrm{C}$-glucose. Recent Prog Horm Res 19:445-488

15. Stacpoole PW, Wright EC, Baumgartner TG, Bersin RM, Buchalter S, Curry SH, Duncan C, Harman EM, Henderson GN, Jenkinson S, Lachin JM, Lorenz A, Schneider SH, Siegel JH, Summer WR, Thompson D, Wolfe CL, Zorovich B (1994) Natural history and course of acquired lactic acidosis in adults. Am J Med 97:47-54

16. Rashkin MC, Bosken C, Baughman RP (1985) Oxygen delivery in critically ill patients. Relationship to blood lactate and survival. Chest 5:580-584

17. Barenbrock M, Hausberg M, Matzkies F, de la Motte S, Schaefer RM (2000) Effects of bicarbonate- and lactate-buffered replacement fluids on cardiovascular outcome in CVVH patients. Kidney Int 58:1751-1757

18. Davenport A, Aulton K, Payne RB, Will EJ (1990) Hyperlactatemia and increasing metabolic acidosis in hepatorenal failure treated by hemofiltration. Renal Failure 12:99-101 
19. Davenport A, Will EJ, Davidson AM (1989) The effect of lactate-buffered solutions on the acid-base status of patients with renal failure. Nephrol Dial Transplant 4:800-804

20. Heering $P$, Ivens $K$, Thürmer $O$, Morgera O, Heintzen M, PasslickDeetjen J, Willers R, Strauer BE, Grabensee B (1999) The use of different buffers during continuous hemofiltration in critically ill patients with acute renal failure. Intensive Care Med 25:1244-1251

21. Kierdorf H, Leue C, Heintz B, Riehl J, Melzer H, Sieberth HG ( 1995) Continuous venovenous hemofiltration in acute renal failure: Is a bicarbonate- or lactate-buffered substitution better? In: Sieberth H, Stummvoll H, Kierdorf $\mathrm{H}$ (eds) Continuous extracorporeal treatment in multiple organ dysfunction syndrome. Vol. 116. Karger, Basel, pp 38-47

22. McLean AG, Davenport A, Cox D, Sweny P (2000) Effects of lactatebuffered and lactate-free dialysate in CAVHD patients with and without liver dysfunction. Kidney Int 58:1765-1772

23. Schetz M, Leblanc M, Murray PT (2002) The acute dialysis quality initiative-part VII: fluid composition and management in CRRT. Adv Ren Replace Ther 9:282-289
24. Stacpoole PW, Wright EC, Baumgartner TG, Bersin RM, Buchalter S, Curry SH, Duncan CA, Harman EM, Henderson GN, Jenkinson S, Lachin JM, Lorenz A, Schneider SH, Siegel JH, Summer WR, Thompson D, Wolfe CL, Zorovich B (1992) A controlled clinical trial of dichloroacetate for treatment of lactic acidosis in adults. N Engl J Med 327:1564-1569

25. Kreisberg RA (1980) Lactate homeostasis and lactic acidosis. Ann Intern Med 92:227-237

26. Malhotra D, Shapiro JI (1996) Pathogenesis and management of lactic acidosis. Curr Opin Crit Care 2:439-448

27. Luft FC (2001) Lactic acidosis update for critical care clinicians. J Am Soc Nephrol 12 (Suppl 17):S15-S19

28. Chiolero R, Mavrocordatos P, Burnier $\mathrm{P}$, Cayeux MC, Schindler C, Jequier E, Tappy L (1993) Effects of infused sodium acetate, sodium lactate and sodium beta-hydroxybutyrate on energy expenditure and substrate oxidation rates in lean humans. Am J Clin Nutr 58:608-613

29. Levraut J, Ciebiera JP, Jambou P, Ichai C, Labib Y, Grimaud D (1997) Effect of continuous venovenous hemofiltration with dialysis on lactate clearance in critically ill patients. Crit Care Med 25:58-62

30. Metnitz PG, Krenn CG, Steltzer H, Lang T, Ploder J, Lenz K, Le Gall JR, Druml W (2002) Effect of acute renal failure requiring renal replacement therapy on outcome in critically ill patients. Crit Care Med 30:2051-2058
31. James JH, Wagner KR, King JK, Leffler RE, Upputuri RK, Balasubramaniam A, Friend LA, Shelly DA, Paul RJ, Fischer JE (1999) Stimulation of both aerobic glycolysis and $\mathrm{Na}^{+}-\mathrm{K}^{+}$-ATPase activity in skeletal muscle by epinephrine or amylin. Am J Physiol 277:E176-E186

32. Van der Poll T, Romijn JA, Endert E, Born JJJ, Büller HR, Sauerwein HP (1991) Tumor necrosis factor mimics the metabolic response to acute infection in healthy humans. Am J Physiol 261:E457-E465

33. Wilmore DW, Aulick LH (1980) Systemic responses to injury and the healing wound. JPEN J Parenter Enteral Nutr 4:147-151

34. Levraut J, Ciebiera JP, Chave S, Rabary O, Jambou P, Charles M, Grimaud D (1998) Mild hyperlactatemia in stable septic patients is due to impaired lactate clearance rather than overproduction. Am J Resp Crit Care Med 157:10211026

35. Tappy L, Chioléro R, Berger M (1999) Autoregulation of glucose production in health and disease. Curr Opin Clin Nutr Metab Care 2:161-164

36. Tappy L, Cayeux MC, Schneiter P, Schindler C, Temler E, Jéquier E, Chioléro R (1995) Effects of lactate on glucose metabolism in healthy subjects and in severely injured hyperglycemic patients. Am J Physiol 268:E630-E635

37. Thomas AN, Guy JM, Kishen R, Geraghty IF, Bowles BJ, Vadgama P (1997) Comparison of lactate and bicarbonate buffered haemofiltration fluids: use in critically ill patients. Nephrol Dial Transplant 12:1212-1217 